\title{
Differential Efficacy of Lithium and Carbamazepine in the Prophylaxis of Bipolar Disorder: Results of the MAP Study
}

\author{
Nikolaus Kleindienst ${ }^{a}$ Waldemar Greila,b \\ aPsychiatric Hospital of the University of Munich, Germany; bPsychiatric Private Clinic Sanatorium Kilchberg, \\ Zurich, Switzerland
}

\author{
Key Words \\ Bipolar disorder - Randomized controlled trial • Lithium • \\ Carbamazepine - Treatment outcome - Suicide, \\ attempted
}

\begin{abstract}
In a randomized clinical trial with an observation period of 2.5 years, the differential efficacy of lithium versus carbamazepine was compared in 171 bipolar patients (DSM-IV). In order to investigate the efficacy of the two drugs in clearly defined subsamples, a series of subgroup analyses was carried out. First, patients with a bipolar I disorder ( $n=114$ ) were analyzed separately. In these patients, lithium was superior to carbamazepine. In contrast, carbamazepine was at least equally as efficacious as lithium in the subsample of patients with bipolar II disorder or bipolar disorder not otherwise specified ( $n=57$ ). In a second analysis on differential efficacy, the whole sample was subdivided into a classical subgroup (bipolar I patients without mood-incongruent delusions and without comorbidity; $\mathrm{n}=67$ ) and a nonclassical subgroup including all other patients $(n=104)$. Classical bipolar patients had a significantly lower hospitalization rate under lithium than under carbamazepine prophylaxis (26 vs. $62 \%, p=0.012$ ). For the nonclassical group, a tendency in favor of carbamazepine was found. In a third
\end{abstract}

\begin{tabular}{ll}
\hline KARGER & ( ) 2000 S. Karger AG, Basel \\
Fax +4161306 1234 & \\
$\begin{array}{l}\text { E-Mail karger@karger.ch } \\
\text { www.karger.com }\end{array}$ & $\begin{array}{l}\text { Accessible online at: } \\
\text { www.karger.com/journals/nps }\end{array}$
\end{tabular}

step, we analyzed the impact of episode sequence on differential efficacy. In a global view, the episode sequence prior to the index episode was not correlated to differential efficacy. Our results might, however, indicate that patients with an episode sequence of mania-depressionfree interval responded better to lithium. Besides differential efficacy, suicidal behavior and patients' satisfaction with treatment were investigated. Regarding suicidal behavior, a trend in favor of lithium was found. The data on patients' satisfaction were significantly in favor of carbamazepine. In conclusion, lithium appears to be superior to carbamazepine in classical bipolar cases and might have additional impact on proneness to suicide. The distinctly larger group of patients with nonclassical features might profit more from carbamazepine which seems to be well accepted by the patients. Hence, treatment alternatives to lithium are desirable for the majority of bipolar patients.

Copyright $@ 2000$ S. Karger AG, Basel

\section{Introduction}

Since lithium first demonstrated prophylactic efficacy in bipolar disorder, the phenomenology of the samples investigated has changed considerably. This is partially due to a shift from the diagnostic systems used in the

Nikolaus Kleindienst, Dipl.-Stat.

Psychiatric Hospital of the University of Munich

Nussbaumstrasse 7

D-80336 Munich (Germany)

Tel. +49 895160 2781, Fax +49895160 4749, E-Mail niko@psy.med.uni-muenchen.de 
Table 1. Monopharmacological treatment strategies in the prophylaxis of bipolar disorder

\begin{tabular}{|c|c|}
\hline Substance & Remarks \\
\hline Lithium & $\begin{array}{l}\text { Efficacy established by several controlled studies } \\
\text { Efficacy seems to be negatively affected by } \\
\text { mood-incongruent delusions } \\
\text { rapid cycling } \\
\text { psychiatric comorbidity } \\
\text { secondary affective disorders } \\
\text { Efficacy seems to be positively influenced by } \\
\text { a typical clinical picture } \\
\text { an episode sequence of MDI }{ }^{1} \\
\text { Some evidence from open studies of antisuicidal efficacy }\end{array}$ \\
\hline Carbamazepine & $\begin{array}{l}\text { Evidence of efficacy from controlled studies } \\
\text { Seems to have a broader spectrum of efficacy than lithium }\end{array}$ \\
\hline Valproate & $\begin{array}{l}\text { Some evidence of efficacy from open studies and from clinical experience } \\
\text { Might be especially helpful in rapid cycling }\end{array}$ \\
\hline $\begin{array}{l}\text { Lamotrigine? } \\
\text { Gabapentine? } \\
\text { Topiramate? } \\
\text { Nimodipine? } \\
\text { Clozapine? } \\
\text { Olanzapine? }\end{array}$ & $\begin{array}{l}\text { Regarding efficacy of these substances, there is only poor evidence } \\
\text { from a few case reports and open studies, } \\
\text { Lamotrigine might be helpful in treating bipolar depression } \\
\text { Nimodipine might be helpful in ultra rapid cycling bipolar disorder } \\
\text { Clozapine might be helpful in schizoaffective disorders }\end{array}$ \\
\hline
\end{tabular}

1960s and 1970s to recent diagnostic manuals such as DSM-IV and ICD-10. The diagnostic criteria for affective disorders have become broader and more differentiated over the last decades. For example, patients who present both manic and schizophrenic symptoms are more readily ascribed to the bipolar disorders as compared to the time when lithium was introduced as prophylactic agent [1-3]. This trend towards the broadening and subclassifying of diagnostic categories is fostered by modern research which pays more attention to mixed states, rapid cycling and subsyndromal affective states [3-8]. In consequence, the spectrum of patients diagnosed as bipolar has become more heterogeneous over time. It is unclear whether lithium, which was proven to be efficacious for quite a specific disorder covers the whole spectrum of bipolarity. There is some evidence that this is not the case, and that alternative treatments are needed [2,9-11].

The first generation of alternative treatments, the anticonvulsants carbamazepine and valproate, has shown beneficial effects in many patients and is well established in the prophylaxis of lithium-nonresponsive bipolar illness [12-17]. Initial data also support prophylactic efficacy of further pharmacological strategies including lamotrigine, gabapentine, nimodipine and olanzapine [18-25] (table 1). Regarding the use of these mood stabilizers, little is known about the prediction of response to different treatment strategies [26] (table 1). First, only a few clinical features for differential indication have been found. Second, the evidence on differential indication is mainly based on uncontrolled studies and case reports that do not allow for definite conclusions. Hence, knowledge on differential efficacy is to be considered as preliminary in most cases and awaits confirmation in prospective randomized clinical trials.

One of the randomized studies on differential efficacy of mood-stabilizers is the Multicenter Study of LongTerm Treatment of Affective and Schizoaffective Psychoses (MAP study). The relevant results of this study regarding efficacy of lithium versus carbamazepine in clearly defined subgroups are summarized in the following text. Data on differential efficacy are supplemented by evaluation of suicidal behavior and patients' satisfaction with lithium and carbamazepine. Patients' satisfaction with a treatment is a crucial issue in compliance, and noncompliance is the limiting factor for efficacy in a major part of the patients $[27,28]$. 


\section{Subjects and Methods}

The MAP study group comprises the psychiatric hospitals of 9 universities in Germany (Aachen, Berlin, Düsseldorf, Heidelberg, Lübeck, München, Münster, Tübingen and Würzburg). In these centers, patients with an affective or schizoaffective episode were

Table 2. Correspondence of diagnoses in DSM-III-R and DSM-IV

\begin{tabular}{lll}
\hline DSM-III-R & & DSM-IV \\
\hline Bipolar & $\stackrel{\text { corresponds to }}{\longrightarrow}$ & Bipolar I \\
Bipolar NOS $^{1}$ & $\stackrel{\text { corresponds to }}{\longrightarrow}$ & $\left\{\begin{array}{l}\text { Bipolar II } \\
\text { Bipolar NOS }\end{array}\right.$ \\
& &
\end{tabular}

$1 \quad$ NOS $=$ Not otherwise specified.

Table 3. Demographic and clinical characteristics at study beginning

\begin{tabular}{|c|c|c|}
\hline & Carbamazepine & Lithium \\
\hline $\mathrm{n}$ & 85 & 86 \\
\hline Sex, $\%$ female & 58 & 55 \\
\hline Age, mean years $\pm \mathrm{SD}$ & $39 \pm 13$ & $41 \pm 13$ \\
\hline \multicolumn{3}{|l|}{ Marital status, $\%$} \\
\hline Never married & 33 & 31 \\
\hline Married & 48 & 52 \\
\hline Separated/divorced & 17 & 16 \\
\hline Widowed & 2 & 0 \\
\hline \multicolumn{3}{|l|}{ Years of Education, $\%$} \\
\hline$\leq 9$ (elementary school) & 52 & 47 \\
\hline 10-12 (secondary school) & 17 & 20 \\
\hline$\geq 13$ (graduate) & 32 & 34 \\
\hline Age at onset, mean years \pm SD & $31 \pm 12$ & $32 \pm 12$ \\
\hline \multicolumn{3}{|l|}{ Suicide attempts, $\%$} \\
\hline None & 63 & 58 \\
\hline 1 & 26 & 30 \\
\hline 2 or more & 11 & 12 \\
\hline \multicolumn{3}{|c|}{ Episodes of illness (including index episode), $\%$} \\
\hline 2 & 21 & 10 \\
\hline $3-10$ & 70 & 76 \\
\hline 11 or more & 8 & 14 \\
\hline \multicolumn{3}{|c|}{ Hospitalizations (including index episode), $\%$} \\
\hline $1-2$ & 51 & 52 \\
\hline $3-10$ & 48 & 48 \\
\hline 11 or more & 1 & 0 \\
\hline \multicolumn{3}{|l|}{ GAS score at study onset } \\
\hline mean $\pm \mathrm{SD}$ & $79 \pm 10$ & $79 \pm 10$ \\
\hline
\end{tabular}

None of the differences is significant (using Fisher's exact test, the $\chi^{2}$ test and the Wilcoxon test, respectively. screened during hospitalization and entered the study if they fulfilled the following criteria: (1) current episode of an affective or schizoaffective disorder according to ICD-9 (296.1-296.4, 296.7); (2) at least one additional episode during the last 5 years (unipolar depression), 4 years (bipolar disorder), 3 years (schizoaffective disorder); (3) no prophylactic treatment immediately before the current episode; (4) no diagnosis of alcohol or drug abuse (current); (5) no contraindication against one of the study medications; (6) age between 18 and 65 years, and (7) informed consent.

As we intended to study the efficacy of maintenance (not continuation) treatment [29], patients entered the study after recovery from the index episode (Global Assessment Scale, GAS, $>70$ for at least 2 weeks within 6 months after discharge [30]). Bipolar and schizoaffective patients received lithium or carbamazepine as study medication. After randomization to prophylactic treatment, the study patients were treated in an outpatient setting during a maintenance phase of 2.5 years. Psychotropic comedication was avoided during the maintenance phase. However, if concomitant medication was judged to be inevitable, it was accepted and documented. A detailed description of the study design is given in Greil et al. [31, 32]. Following a polydiagnostic approach, patients were diagnosed not only according to ICD-9 but also according to DSM-III-R using the Structured Clinical Interview of Mental Disorders and according to RDC [33]. This paper summarizes the results on bipolar patients according to DSMIII-R using DSM-IV terminology. The exact correspondence between these diagnostic systems is given in table 2 .

To make sure that the results do not depend on the specific definition of a treatment failure, different failure criteria were formulated for statistical analyses (for details see Greil et al. [32]): (1) hospitalization, (2) recurrence, (3) recurrence and/or concomitant psychotropic medication (antidepressants and/or neuroleptics) for at least 6 months, (4) recurrence and/or concomitant psychotropic medication and/or side effects prompting discontinuation of treatment and (5) recurrence and/or subclinical recurrence. In the present paper, data are presented with respect to hospitalization, but we always indicate whether the results depend on the way efficacy has been analyzed. In this case, additional data regarding the other outcome criteria are provided.

\section{Statistical Analyses}

The statistical evaluation of the failure rates, dropouts and side effects was done by Fisher's exact test. The association between treatment outcome and the number of nonclassical diagnostic features was evaluated using Mantel-Haenszel statistics [34]. These tests are based on the failure rates of the patients who completed the study according to protocol (ATP). ATP analyses were corroborated by Kaplan-Meier estimates of the survival curves based on intentionto-treat data [35]. Survivor functions were tested for equality using Tarone-Ware statistics [36].

\section{Results}

\section{Study Patients}

Of the 171 patients with a diagnosis of bipolar disorder (DSM-IV), 86 had been randomized to lithium and 85 to carbamazepine. No significant differences between the treatment groups were found in clinical and sociodemo- 
graphic variables including sex, age, family history of affective disorders, age at onset of illness, number of previous episodes, GAS score [30] at study onset and acute treatment of the index episode (table 3 ).

In the acute treatment of the index episode, lithium and carbamazepine played only a minor role $(9 \%$ of the patients treated with lithium and $8 \%$ treated with carbamazepine). The average dose during the maintenance phase (between month 2 and study termination) was 26.8 $\pm 6.76 \mathrm{mmol} /$ day for lithium (serum level $0.61 \pm 0.12$ $\mathrm{mmol} / \mathrm{l}$ ) and $635 \pm 190 \mathrm{mg} /$ day for carbamazepine (serum level $6.12 \pm 1.27 \mu \mathrm{g} / \mathrm{ml}$ ).

\section{Dropout Patients}

As compared to lithium, more patients treated with carbamazepine dropped out of the study before having a recurrence ( 12 vs. $28 ; p=0.004$, Fisher's exact test). Reasons for noncompletion are summarized in table 4 .

\section{Bipolar I versus Bipolar II/Not Otherwise Specified}

In a first subgroup analysis, efficacy of lithium and carbamazepine was compared in patients with bipolar I and in patients with bipolar II or bipolar disorder not otherwise specified (NOS), respectively. In bipolar I patients, the failure rate was about 50\% higher in the carbamazepine group for all failure criteria (table 5). This result is significant for the broader failure criteria $3-5$, which are very sensitive in detecting differences between treatment strategies [37]. These results have been substantiated by survival analyses (not shown). All data consistently suggest that lithium was clearly more efficacious than carbamazepine in the maintenance treatment of bipolar I patients.
Regarding bipolar II/NOS patients, the results are far less conclusive for several reasons. As can be seen from table 6 , the results on comparative efficacy of lithium and carbamazepine are substantially influenced by the choice of the outcome criterion. It is also difficult to attribute the results to a precise diagnostic group as the subsample of bipolar II/NOS patients is quite heterogeneous compris-

Table 4. Reasons for noncompletion (dropouts)

\begin{tabular}{lll}
\hline $\begin{array}{l}\text { Reasons for } \\
\text { noncompletion }\end{array}$ & $\begin{array}{l}\text { Carbamazepine } \\
(\mathrm{n}=85)\end{array}$ & $\begin{array}{l}\text { Lithium } \\
(\mathrm{n}=86)\end{array}$ \\
\hline $\begin{array}{l}\text { Treatment-related reasons } \\
\text { Unwanted side effects }\end{array}$ & 8 & 3 \\
Inefficacy of therapy $^{2}$ & 2 & 0 \\
\hline Protocol violations $^{\text {Contraindication }}{ }^{3}$ & 3 & 0 \\
Other reasons $^{4}$ & 15 & 9 \\
\hline $\mathrm{n}$ & 28 & 12 \\
\hline
\end{tabular}

1 Under carbamazepine: exanthema, swollen lymphoma and headache (1 patient), allergy and rash (1), generalized eczema (1), allergic skin reaction (1), hepatopathy (1), swollen lymphoma and diarrhea (1), exanthema. Under lithium: vertigo, nausea and headache (1), acne and weight gain (1), disturbances of potency (1).

2 Discontinuation by the physician because of long-term need of concomitant medication.

3 Pregnancy (2 patients) and change of diagnosis (1).

4 This category comprises patients in whom noncompletion seemed not to be related to the treatment, e.g. external circumstances or decision against further treatment without clear reasons.

Table 5. Failure rates for lithium and carbamazepine in bipolar I patients

\begin{tabular}{|c|c|c|c|c|}
\hline Failure criterion & $\begin{array}{l}\text { Carbamazepine } \\
(\mathrm{n}=56) \\
\text { failure rates, } \%\end{array}$ & $\begin{array}{l}\text { Lithium } \\
(\mathrm{n}=58) \\
\text { failure rates, } \%\end{array}$ & $\begin{array}{l}\text { Relative } \\
\text { risk }\end{array}$ & $\mathrm{p}$ \\
\hline Hospitalization & 55 & 37 & 1.49 & 0.09 \\
\hline Recurrence & 59 & 40 & 1.49 & 0.09 \\
\hline Recurrence and/or concomitant medication & 67 & 44 & 1.52 & 0.04 \\
\hline $\begin{array}{l}\text { Recurrence and/or concomitant medication } \\
\text { and/or side effects }\end{array}$ & 71 & 46 & 1.54 & 0.01 \\
\hline Recurrence and/or subclinical recurrence & 71 & 48 & 1.48 & 0.04 \\
\hline
\end{tabular}

The percentages refer to completers according to protocol (ATP). The exact number of completers depends on the failure criterion (for details see Greil et al. [38, 39]). The relative risk is the risk for a treatment failure under carbamazepine divided by the risk for a treatment failure under lithium. Significances were determined by Fisher's exact test. 
Table 6. Failure rates for lithium and carbamazepine in bipolar II/NOS patients

\begin{tabular}{|c|c|c|c|c|c|c|}
\hline \multirow[t]{2}{*}{ Failure criterion } & \multicolumn{2}{|c|}{$\begin{array}{l}\text { Carbamazepine }(\mathrm{n}=29) \\
\text { failure rates, } \%\end{array}$} & \multicolumn{2}{|c|}{$\begin{array}{l}\text { Lithium }(\mathrm{n}=28) \\
\text { failure rates, } \%\end{array}$} & \multirow[t]{2}{*}{$\begin{array}{l}\text { Relative } \\
\text { risk }\end{array}$} & \multirow[t]{2}{*}{$\mathrm{p}$} \\
\hline & $\begin{array}{l}\text { bipolar } \\
\text { II }(n=14)\end{array}$ & $\begin{array}{l}\text { bipolar } \\
\operatorname{NOS}(n=15)\end{array}$ & $\begin{array}{l}\text { bipolar } \\
\text { II }(n=9)\end{array}$ & $\begin{array}{l}\text { bipolar } \\
\text { NOS }(\mathrm{n}=19)\end{array}$ & & \\
\hline Hospitalization & 14 & 7 & 0 & 37 & 0.50 & 0.29 \\
\hline Recurrence & 28 & 7 & 11 & 37 & 0.73 & 0.73 \\
\hline Recurrence and/or concomitant medication & 36 & 33 & 33 & 37 & 1.11 & 1.00 \\
\hline $\begin{array}{l}\text { Recurrence and/or concomitant medication } \\
\text { and/or side effects }\end{array}$ & 50 & 33 & 33 & 47 & 0.91 & 1.00 \\
\hline Recurrence and/or subclinical recurrence & 50 & 27 & 78 & 53 & 0.78 & 0.35 \\
\hline
\end{tabular}

The percentages refer to completers according to protocol (ATP). The exact number of completers depends on the failure criterion (for details see Greil et al. [38, 39]). The distinction between bipolar I and bipolar NOS was made according to RDC criteria [33]. The relative risk is the risk for a treatment failure under carbamazepine divided by the risk for a treatment failure under lithium. The relative risk refers to the entire subsample of bipolar II/NOS patients. Significances were determined by Fisher's exact test.

ing bipolar II patients and different types of bipolar patients not otherwise specified. Finally, the case numbers are too small to allow for definite conclusions.

When we cautiously try to summarize the data on the bipolar II/NOS patients, it appears that in contrast to bipolar I patients, carbamazepine was at least equally as efficacious as lithium. With respect to hospitalization and recurrences as failure criteria, a tendency in favor of carbamazepine might be attributed to the bipolar NOS subsample (failure rate 7 vs. $37 \%$ ). This attribution is, however, not that clear for the other failure criteria (table 6).

\section{The Impact of Nonclassical Features}

Besides the distinction between bipolar I and bipolar II/NOS, further subclassification was done in order to test the hypothesis that lithium is selectively efficacious in classical bipolar patients. The entire sample of bipolar patients (DSM-IV) was subdivided into a classical subgroup (bipolar I patients without mood-incongruent delusions and without psychiatric comorbidity; $n=67$ ) and a nonclassical subgroup including all other patients $(\mathrm{n}=$ 104). Classical bipolar patients had a lower hospitalization rate under lithium than under carbamazepine prophylaxis ( 26 vs. $62 \%, p=0.012$ ). For the nonclassical group, a tendency in favor of carbamazepine was found (44 vs. $31 \%, p=0.34$ ).

As can be seen from figure 1, there was a positive association in the lithium group between hospitalization rate and the number of nonclassical features (bipolar II/NOS, mood-incongruent delusions, comorbidity; $\mathrm{p}=0.035$ ). For carbamazepine, this association was negative $(\mathrm{p}=$
Table 7. Hospitalization rate (ATP) in relation to episode sequence

\begin{tabular}{lcc}
\hline $\begin{array}{l}\text { Episode sequence immediately } \\
\text { before the index episode }\end{array}$ & Carbamazepine & Lithium \\
\hline Depression & $40 \%(8 / 20)$ & $41 \%(9 / 22)$ \\
Mania & $25 \%(2 / 8)$ & $39 \%(7 / 18)$ \\
MDI & $75 \%(3 / 4)$ & $0 \%(0 / 7)$ \\
DMI & $0 \%(0 / 6)$ & $11 \%(1 / 9)$ \\
Other & $61 \%(11 / 18)$ & $53 \%(10 / 19)$ \\
\end{tabular}

$0.033)$. When other outcome criteria such as recurrence or subclinical recurrence are applied, the results regarding the negative relationship between nonclassical features and lithium response were fully confirmed with $p$ values ranging from 0.002 to 0.07 . Regarding carbamazepine response, the relation was only confirmed as a trend ( $p$ values ranging from 0.07 to 0.27 ). Case numbers are too small to determine the exact contribution of each of these nonclassical criteria (for details see Greil et al. [38]).

\section{The Impact of Episode Sequence}

In order to investigate the impact of the episode sequence on differential efficacy, a standardized rating of the patients' history was used. At study entry, the episode immediately before the index episode has been categorized as 'mania', 'depression', 'MDI' (sequence maniadepression-free interval), 'DMI' (sequence depressionmania-free interval) or 'other' (e.g. mixed, schizoaffective, continuous cycling). 
Fig. 1. Failure rates (hospitalization).

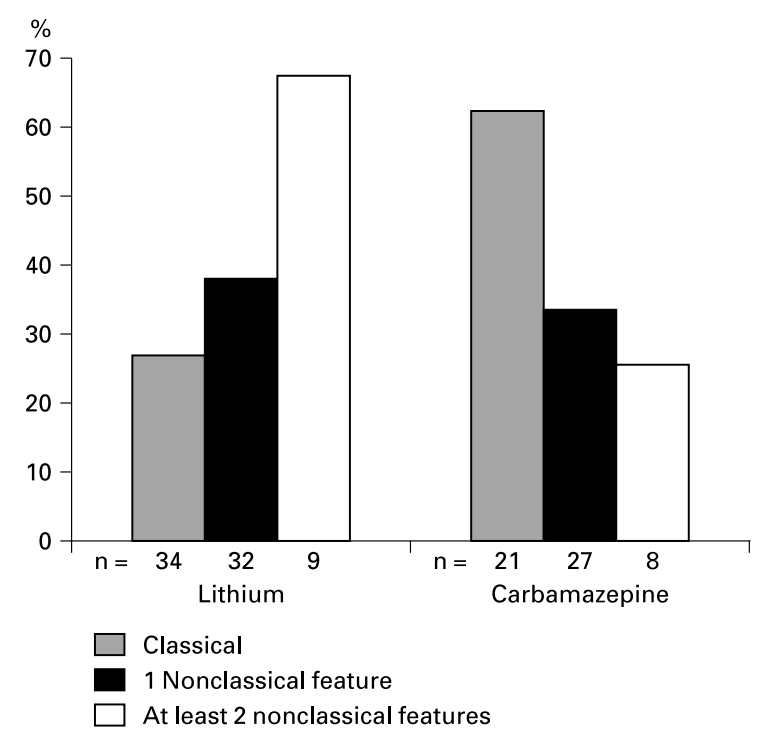

Table 8. Suicidal behavior in patients randomized to lithium or carbamazepine

\begin{tabular}{|c|c|c|c|c|}
\hline & \multicolumn{2}{|c|}{$\begin{array}{l}\text { Bipolar (DSM-IV) } \\
(\mathrm{n}=171)\end{array}$} & \multicolumn{2}{|c|}{$\begin{array}{l}\text { Bipolar or schizoaffective } \\
\left(\text { ICD-9) }(\mathrm{n}=285)^{1}\right.\end{array}$} \\
\hline & lithium & carbamazepine & lithium & carbamazepine \\
\hline Suicide during study period & 0 & 0 & 0 & 1 \\
\hline Attempted suicide during study period & 0 & 4 & 0 & 5 \\
\hline
\end{tabular}

$1285=171$ (bipolar according to DSM-IV) + 114 (bipolar or schizoaffective according to ICD-9, but not bipolar according to DSM-IV).

In a global view, the episode sequence prior to the index episode was not correlated to differential efficacy (total $\chi^{2}=10.2$, d.f. $=8$; table 7). Our results might, however, indicate that patients with an episode sequence of MDI had a lower hospitalization rate under lithium as compared to carbamazepine (0 vs. $75 \%$; table 7 ). Similar results are obtained when the other outcome criteria are applied. From a nosological point of view, it is also notable that this episode sequence (MDI) was significantly correlated to the absence of nonclassical features $(\varphi=$ $0.23, \mathrm{p}=0.0059$ ).

\section{Suicidal Behavior}

In the sample of patients with a diagnosis of bipolar disorder (DSM-IV), 4 suicide attempts were observed during the treatment period. These patients were on carbamazepine at the time they attempted suicide (table 8). Considering all patients who had been randomized to lithium or carbamazepine (i.e. all bipolar and schizoaffective patients according to ICD-9; see Subjects and Methods), 1 additional suicide attempt and 1 completed suicide were observed. All of the 6 suicides occurred in the carbamazepine group (table 8 ). These data refer to the controlled treatment period. When additional data from the time before and after the controlled observation period is taken into account, 3 more suicidal acts were observed (not shown). Again, all 3 patients were under carbamazepine and none under lithium at the time they committed suicide [40]. 


\section{Side Effects and Patients' Satisfaction}

Side effects leading to discontinuation were more frequent under carbamazepine as compared to lithium (8 vs. 3 , n.s.; table 4). The most frequently observed side effect leading to carbamazepine-discontinuation was allergic skin reactions at the beginning of the treatment (for details see Greil et al. [41, 42]).

Side effects were also analyzed after exclusion of those occurring at the beginning of the treatment period. In contrast to the data regarding initial side effects leading to discontinuation, global ratings of the severity of side effects after 1, 2 and 2.5 years were all in favor of carbamazepine. At the end of study period, at least slight side effects were reported by $55 \%$ of the patients treated with lithium as compared to $24 \%$ of the patients under carbamazepine $(\mathrm{p}=0.0006)$.

The satisfaction with treatment in general at the end of the observation period was higher in the carbamazepine group (86 vs. 79 on a $100-\mathrm{mm}$ visual analogue scale, $\mathrm{p}=$ 0.026 , Wilcoxon test).

\section{Discussion}

Patients with a classical presentation of the manicdepressive illness were more likely to respond to prophylactic lithium as compared to carbamazepine. In our interpretation, a classical manic-depressive patient has a diagnosis of bipolar I disorder without mood-incongruent features and without psychiatric comorbidity. The high response rates of lithium in these patients are also supported by the fact that this treatment was very efficacious in patients with the classical episode sequence of MDI. The less a patient resembled the classical type, the higher was the relative efficacy of carbamazepine. This is a robust finding that is largely independent of the failure criterion investigated and the statistical methodology applied.

The data presented in this paper stem from a randomized prospective study. The recruitment process was carefully documented in order to investigate whether the study sample is representative. When comparing the patients who participated in the study to those who fulfilled the inclusion criteria without entering the treatment phase, no major differences regarding clinical and sociodemographic variables were found [31, 38]. Hence, we assume that the enrollment did not result in a substantial bias. Similarly, the randomization is considered to be successful as no significant differences between the treatment groups were found regarding these clinical and sociode- mographic variables. Care was taken to avoid contamination of the results due to withdrawal effects and to study efficacy of maintenance (not continuation) treatment. With respect to episode frequency, the observation period of 2.5 years was long enough to achieve adequate statistical power.

The study was kept nonblind on purpose. It would have been difficult to carry out a blind study over 2.5 years with two substances that present a clearly different side effect profile. In the study on lithium and carbamazepine of Watkins et al. [43] blindness could not be kept, and there has been serious doubt in the validity of the double-blind design in long-term trials [44]. In our study, it cannot be excluded that because of the more recent introduction of carbamazepine as a mood stabilizer, the physicians were less confident in the efficacy of carbamazepine as compared to lithium. This might have led them to discontinue treatment with carbamazepine earlier than a treatment with lithium. However, reasons for dropout appear quite appropriate and do not seem to be related to an excessive cautiousness of the participating psychiatrists [41, 42]. Nevertheless, the present results might be biased by the clinical experience of the physicians.

The data presented on the differential efficacy of lithium and carbamazepine are in line with several observations on the response to prophylactic lithium published over the last decades. As early as 1967 Baastrup and Schou [45] noted that 'lithium is highly effective in purely affective disorders' and have found 'a considerable tendency to relapse ... when the picture shows atypical features'. In Baastrup and Schou [45], atypical features mainly refer to mood-incongruent delusions. The negative influence of this feature on lithium response has been confirmed in several retrospective studies [46, 47]. Similarly, the negative association between psychiatric comorbidity [47, 48] and lithium response and the positive influence of an episode sequence MDI [49-51] have been found previously. Further clinical features that have been reported to be negative predictors for lithium prophylaxis are rapid cycling and mixed states [52]. In our study, rapid cycling could not be investigated as a further predictor of differential response. Due to the stabilization period of several months after discharge before entry into the study, these patients were excluded according to the study protocol. Corresponding to the strict criteria of DSM-IV, a mixed state in the index episode was diagnosed in only $7 \%$ $(\mathrm{n}=8)$ of the patients. Hence, mixed states were only investigated in additional analyses which support the conclusion that lithium is more efficacious than carbamazepine in typical manic-depressive patients (for details see 
Greil et al. [38]). The observed efficacy of lithium versus carbamazepine does not seem to be caused by the enzyme-inducing properties (leading to reduced blood levels of comedication) of the latter drug, since similar results have been obtained in patients with and without concomitant psychotropic medication [39].

The majority of the patients were classified as nonclassical. Besides the broadening of diagnostic criteria, this might be attributed to a selection bias that results from the fact that the patients were recruited in university hospitals. Patients with more atypical, treatment-unresponsive illness may be overrepresented in most research centers $[8,53]$. In general, the use of lithium is limited by its narrow therapeutic range and its disturbing side effects [54, 55]. Furthermore, affective episodes may reappear in patients after several years of an apparently successful lithium prophylaxis [56]. Hence, treatment alternatives to lithium are desirable in a high percentage of patients with bipolar disorder.
The large nonclassical subgroup might be of special interest in designing future clinical trials investigating the efficacy of newer mood stabilizers such as valproate or lamotrigine. Valproate has shown beneficial effects in the prophylaxis of rapid-cycling $[14,15,57,58]$ and ultra-rapid-cycling bipolar disorders [59] as well as in the acute treatment of mania and mixed states [60-62]. Lamotrigine may be especially helpful in the prophylaxis of rapid cycling and in the acute treatment of bipolar depression [18, 63]. Further studies on the efficacy of anticonvulsants in clearly defined subgroups of bipolar patients would be beneficial for the development of treatment algorithms and might also stimulate nosological and biochemical research.

\section{Acknowledgement}

The results of this paper partially stem from Nikolaus Kleindienst's dissertation which is in preparation at the Medical Faculty of the Ludwig-Maximilians-University, Munich.

\section{References}

1 Stoll AL, Tohen M, Baldessarini RJ, Goodwin DC, Stein S, Katz S, Geenens D, Swinson RP, Goethe JW, McGlashan T: Shifts in diagnostic frequencies of schizophrenia and major affective disorders at six North American psychiatric hospitals, 1972-1988. Am J Psychiatry 1993; 150:1668-1673.

2 Grof P: Has the effectiveness of lithium changed? Impact of the variety of lithium's effects. Neuropsychopharmacology 1998;19: 183-188.

3 Grof P, Alda M: Discrepancies in the efficacy of lithium. Arch Gen Psychiatry 2000;57:191.

4 Dunner DL: Differential diagnosis of bipolar disorder. J Clin Psychopharmacol 1992;12:7S$12 \mathrm{~S}$.

5 Dunner DL: Bipolar Disorder in DSM-IV: Impact of inclusion of rapid cycling as a course modifier. Neuropsychopharmacology 1998;19: 189-193.

6 Akiskal HS: The prevalent clinical spectrum of bipolar disorders: Beyond DSM-IV. J Clin Psychopharmacol 1996;16(suppl 1):4S-14S.

7 Zarate CA Jr, Tohen M, Baraibar G, Zarate SB, Baldessarini RJ: Shifts in hospital diagnostic frequencies: Bipolar disorder subtypes, 19811993. J Affect Disord 1997;43:79-84.

8 Goodwin FK, Ghaemi SN: Understanding manic-depressive Illness. Arch Gen Psychiatry 1998;55:23-25.

9 Post RM, Ketter TA, Dennicoff K, Pazzaglia PJ, Leverich GS, Marangell AM, Callalian AM, George MS, Frye MA: The place of anticonvulsant therapy in bipolar illness. Psychopharmacology 1996;128:115-129.
10 Gershon S, Soares JC: Current therapeutic profile of lithium. Arch Gen Psychiatry 1997;54: 16-20.

11 Schou M: Has the time come to abandon prophylactic lithium treatment? A review for clinicians. Pharmacopsychiatry 1998;31:210-215.

12 Emrich HM, Okuma T, Müller AA (eds): Anticonvulsants in Affective Disorders. Amsterdam, Excerpta Medica, 1984.

13 McElroy SL, Keck PE Jr, Pope HG Jr, Hudson JI: Valproate in the treatment of bipolar disorder: Literature review and clinical guidelines. J Clin Psychopharmacol 1992;12:42S-52S.

14 Calabrese JR, Rapport DJ, Kimmel SE, Reece B, Woyshville MJ: Rapid cycling bipolar disorder and its treatment with valproate. Can J Psychiatry 1993;38:S57-S61.

15 Calabrese JR, Bowden C, Woyshville MJ: Lithium and the anticonvulsants in the treatment of bipolar disorder; in Bloom FE, Kupfer DJ (eds): Psychopharmacology. The Fourth Generation of Progress. New York, Raven Press, 1995, pp 1099-1111.

16 Dardennes R, Even C, Bange F, Heim A: Comparison of carbamazepine and lithium in the prophylaxis of bipolar disorder. A meta-analysis. Br J Psychiatry 1995; 166:378-381.

17 Post RM, Denicoff K, Frye MA, Leverich GS: Re-evaluating carbamazepine prophylaxis in bipolar disorder. Br J Psychiatry 1997;170: 202-204.

18 Fatemi SH, Rapport DJ, Calabrese JR, Thuras $\mathrm{P}$ : Lamotrigine in rapid-cycling bipolar disorder. J Clin Psychiatry 1997;58:522-527.

19 Zarate CA Jr, Tohen JM, Banov MD, Weiss MK, Cole JO: Is clozapine a mood stabilizer? J Clin Psychiatry 1995;56:108-112.
20 Sarfati Y, Spadone C, Vanelle JM, Loo H: Inhibiteurs calciques et lithium dans le traitement prophylactique de la maladie maniacodépressive. Encéphale 1996;22:149-153.

21 Schaffer CB, Schaffer LC: Gabapentin in the treatment of bipolar disorder. Am J Psychiatry 1997;154:291-292.

22 Tohen M, Zarate CA Jr: Antipsychotic agents and bipolar disorder. J Clin Psychiatry 1998; 59(suppl 1): 38-48.

23 Keck PE Jr, McElroy SJ, Strakowski SM: Anticonvulsants and antipsychotics in the treatment of bipolar disorder. J Clin Psychiatry 1998;59(suppl 6): 74-81.

24 Marcotte D, Gullick A: Use of topiramte, a new antiepileptic, as a mood stabilizer. J Affect Disord 1998;50:245-251.

25 Grunze H, Schlösser S, Amann B, Walden J: Anticonvulsant drugs in bipolar disorder. Dialogues Clin Neurosci 1999;1:24-40.

26 Solomon DA, Keitner DI, Miller IW, Shea MT, Keller MB: Course of illness and maintenance treatments for patients with bipolar disorder. $\mathrm{J}$ Clin Psychiatry 1995;56:5-13.

27 Maarbjerg K, Aagaard J, Vestergaard P: Adherence to lithium prophylaxis. I. Clinical predictors and patient's reasons for nonadherence. Pharmacopsychiatry 1988;21:121-125.

28 Guscott R, Taylor L: Lithium prophylaxis in recurrent affective illness. $\mathrm{Br} \mathrm{J}$ Psychiatry 1994;164:741-746.

29 Kupfer DJ: Long-term treatment of depression. J Clin Psychiatry 1991;52(suppl 5):28-34.

30 Endicott J, Spitzer RL, Fleiss JL, Cohen J: The global assessment scale. A procedure for measuring overall severity of psychiatric disturbance. Arch Gen Psychiatry 1976;33:766-771. 
31 Greil W, Ludwig-Mayerhofer W, Steller B, Czernik A, Giedke H, Müller-Oerlinghausen B, Osterheider M, Rudolf GAE, Sauer H, Tegeler $\mathrm{J}$, Wetterling T: The recruitment process for a multicenter study on the long-term prophylactic treatment of affective disorders. J Affect Disord 1993;28:257-265.

32 Greil W, Ludwig-Mayerhofer W, Erazo N, Engel RR, Czernik A, Giedke H, Müller-Oerlinghausen B, Osterheider M, Rudolf GAE, Sauer H, Tegeler J, Wetterling T: Comparative efficacy of lithium and amitriptyline in the maintenance treatment of recurrent unipolar depression: A randomised study. J Affect Disord 1996;40:179-190.

33 Spitzer RL, Endicott J, Robins E: Forschungsdiagnosekriterien (RDC). Weinheim, Belz, 1982.

34 Mantel N: Chi-square tests with one degree of freedom; extension of the Mantel-Haenszel procedure. J Am Stat Assoc 1963;58:690-700.

35 Kaplan EL, Meier P: Nonparametric estimation from incomplete observations. J Am Stat Assoc 1958;53:457-481.

36 Tarone RE, Ware J: On distribution-free tests for equality of survival distributions. Biometrica 1977;64:156-160.

37 Montgomery SA, Dunbar G: Paroxetine is better than placebo in relapse prevention and the prophylaxis of recurrent depression. Int Clin Psychopharmacol 1993;8:189-195.

38 Greil W, Kleindienst N, Erazo N, Müller-Oerlinghausen B: Differential response to lithium and carbamazepine in the prophylaxis of bipolar disorder. J Clin Psychopharmacol 1998;18: 455-460.

39 Greil W, Kleindienst N: The comparative prophylactic efficacy of lithium and carbamazepine in patients with bipolar I disorder. Int Clin Psychopharmacol 1999;14:277-281.

40 Thies-Flechtner K, Müller-Oerlinghausen B, Seibert W, Walther A, Greil W: Effect of prophylactic treatment on suicide risk in patients with major affective disorders. Pharmacopsychiatry 1996;29:103-107.

41 Greil W, Ludwig-Mayerhofer W, Erazo N, Engel RR, Czernik A, Giedke H, Müller-Oerlinghausen B, Osterheider M, Rudolf GAE, Sauer $\mathrm{H}$, Tegeler J, Wetterling T: Lithium versus carbamazepine in the maintenance treatment of schizoaffective disorder: A randomised study. Eur Arch Psychiatry Clin Neurosci 1997;247: $42-50$
42 Greil W, Ludwig-Mayerhofer W, Erazo N, Schöchlin C, Schmidt S, Engel RR, Czernik A, Giedke H, Müller-Oerlinghausen B, Osterheider M, Rudolf GAE, Sauer H, Tegeler J, Wetterling T: Lithium versus carbamazepine in the maintenance treatment of bipolar disorders: A randomized study. J Affect Disord 1997;43:151-161.

43 Watkins SE, Callender K, Thomas DR, Tidmarsh SF, Shaw DM: The effect of carbamazepine and lithium on remission from affective illness. Br J Psychiatry 1987;150:180-182.

44 Oxtoby A, Jones A, Robinson M: Is your 'double-blind' design truly double-blind? Br J Psychiatry 1989;155:700-701

45 Baastrup PC, Schou M: Lithium as a prophylactic agent. Its effect against recurrent depressions and manic-depressive psychosis. Arch Gen Psychiatry 1967;16:162-172.

46 Hanus H, Zapletalek M: The prophylactic lithium treatment in affective disorders and the possibilities of the outcome prediction. Sb Ved Pr Lek Fak Karlovy Univerzity Hradci Kralove 1984;27:5-75.

47 Kusalic M, Engelsmann F: Predictors of lithium treatment responsiveness in bipolar patients. A two-year prospective study. Neuropsychobiology 1998;37:146-149.

48 O'Connell RA, Mayo JA, Flatow L, Cuthbertson B, O'Brien BE: Outcome of bipolar disorder on long-term treatment with lithium. $\mathrm{Br} \mathrm{J}$ Psychiatry 1991;159:123-129.

49 Kukopulos A, Reginaldi D, Laddomada P, Floris $\mathrm{G}$, Serra $\mathrm{G}$, Tondo L: Course of the manicdepressive cycle and changes caused by treatments. Pharmacopsychiatry 1980;13:156-167.

50 Haag M, Heidorn A, Haag H, Greil W: Response to stabilising lithium therapy and sequence of affective polarity. Pharmacopsychiatry 1986;19:278-279.

51 Grof E, Haag M, Grof P, Haag H: Lithium response and the sequence of episode polarities: Preliminary report on a Hamilton sample. Prog Neuropsychopharmacol Biol Psychiatry 1987;11:199-203.

52 Calabrese JR, Fatemi SH, Kujawa M, Woyshville MJ: Predictors of response to mood stabilizers. J Clin Psychopharmacol 1996;16(suppl 1): $24 \mathrm{~S}-31 \mathrm{~S}$.
53 Baldessarini RJ, Tondo MD: Does lithium treatment still work? Arch Gen Psychiatry 2000;57:187-190.

54 Schou M, Hansen HE, Thomsen K, Vestergaard P: Lithium treatment in Aarhus. 2. Risk of renal failure and of intoxication. Pharmacopsychiatry 1989;22:101-103.

55 Goodwin FK, Jamison KR: Manic-Depressive Illness. New York, Oxford University Press, 1990.

56 Kleindienst N, Greil W, Rüger B, Möller HJ: The prophylactic efficacy of lithium - Transient or persistent? Eur Arch Psychiatry Clin Neurosci 1999;249:144-149.

57 Lambert PA: Acute and prophylactic therapies of patients with affective disorders using valpromide (Dipropylacetamide); in Emrich HM, Okuma T, Müller AA (eds): Anticonvulsants in Affective Disorders. Amsterdam, Excerpta Medica, 1984:33-44.

58 Hayes S: Long-term use of valproate in primary psychiatric disorders. J Clin Psychiatry 1989; 50(suppl): 35-39.

59 Juckel G, Hegerl U, Mavrogiorgou P, Gallinat J, Mager T, Tigges P, Dresel S, Schröter A, Stotz G, Meller I, Greil W, Möller HJ: Clinical and biological findings in a case with 48-hour bipolar ultra-rapid cycling before and under valproate treatment. J Clin Psychiatry 2000; 61:585-591.

60 Swann AC, Bowden CL, Morris D, Calabrese JR, Petty F, Small J, Dilsaver SC, Davis JM: Depression during mania. Treatment response to lithium or divalproex. Arch Gen Psychiatry 1997;54:37-42.

61 Bowden CL, Brugger AM, Swann AC, Calabrese JR, Janicak PG, Petty F, Dilsaver SC, Davis JM, Rush AJ, Small JG, Garza-Trevino ES, Risch SC, Goodnick PJ, Morris DD: Efficacy of divalproex vs lithium and placebo in the treatment of mania. The Depakote Mania Study Group. JAMA 1994;271:918-924.

62 Bowden CL: Predictors of response to divalproex and lithium. J Clin Psychiatry 1995; 56(suppl 3): 25-30.

63 Calabrese JR, Fatemi SH, Woyshville MJ: Antidepressant effects of lamotrigine in rapid cycling bipolar disorder. Am J Psychiatry 1996; 153:1236. 